\title{
Evidence for a lipid specific effect in nutrient induced human proximal gastric relaxation
}

\author{
J T McLaughlin, L E A Troncon, J Barlow, L J Heggie, D G Thompson
}

\begin{abstract}
BackgroundlAim-The presence of lipid in the upper gut is able to modify gastrointestinal motor performance, but its influence on the relaxation of the human stomach, which is known to modify gastric emptying, remains incompletely understood. The relaxation of the proximal stomach in response to various lipid concentrations was therefore studied in healthy volunteers. Since the observed effects could be mediated through osmolality or energy sensitive pathways, the effects of equicaloric and equiosmolar non-lipid solutions were also determined. Methods-The tone of the proximal stomach was measured during stepwise inflation of a non-compliant bag sited in the proximal stomach, both before and after a test meal was delivered intragastrically. Iso-osmolar lipid emulsions were diluted in iso-osmolar saline at concentrations of $1.25,2.5,5,10$, and $20 \%$. $\mathrm{NaCl}$ solutions at osmolalities of $300,600,1200$ and 2400 mmol/kg and glucose solutions of 836 and $3344 \mathrm{~kJ} / 1$ were also given.
\end{abstract}

Results-All lipid meals of $2.5 \%$ or greater concentration induced a reduction in gastric tone in a non-dose-dependent manner, responses to $5 \%$ lipid (median (range) $74(62-92) \%)$ being similar to those to $20 \%$ lipid $(80(55-83) \% ; p>0.05)$. No relaxation was elicited by isocaloric glucose. $\mathrm{NaCl}$ only consistently caused relaxation at 2400 mmol/kg.

Conclusion-Lipid meals reduce human proximal gastric tone by a lipid specific mechanism, independently of their energy content or osmolality.

(Gut 1998;43:248-251)

Keywords: lipid; gastrointestinal motor performance; proximal stomach; osmolality; energy

University of

Manchester,

Department of

Medicine,

Hope Hospital,

Eccles Old Road,

Salford M6 8HD, UK

$\mathrm{J}$ T McLaughlin

LE A Troncon

J Barlow

L J Heggie

D G Thompson

Correspondence to:

D G Thompson.

Accepted for publication 4 March 1998

The presence of lipid in the upper gastrointestinal tract has been shown to influence its function in a number of ways. Ewald and Boas ${ }^{1}$ in 1886 first showed that the addition of olive oil delayed the gastric emptying of gruel in dogs, an effect that was later replicated in many other species including man. ${ }^{2}{ }^{3}$ Lipid effects on the stomach are region specific: they inhibit antral contractility ${ }^{4}$ but increase pyloric tone. ${ }^{56}$ Relaxation of the fundus is also induced by lipid, resulting in a rise in intragastric volume without a parallel change in pressure. ${ }^{7}$ The extent to which lipid influences the proximal human stomach remains unknown however, because measurements of human fundal performance have hitherto been limited by methodological difficulties. The recent development of computer controlled distension techniques now provides the opportunity to study postprandial gastric tone in humans. ${ }^{8}$ Using such a technique we have recently reported the pressure-volume relations of the proximal stomach in healthy volunteers and described proximal gastric relaxation responses to a mixed nutrient meal. ${ }^{8}$

The purpose of the current study was to explore the effect of lipid on human fundal relaxation, using a series of meals varying in lipid concentration. The possibility that the energy content or osmolar load of these lipid meals could have been responsible for any of the effects seen was also explored by the use of non-lipid meals, matched for these parameters.

\section{Methods}

SUBJECTS

Fifteen healthy volunteers (seven men and eight women; median age 26 range $20-29$ years) participated in the study after giving written informed consent. All were recruited from the staff and student population of Manchester University. None had any past history of digestive system disease and none were taking medication which might affect gastric motility. The study protocol was approved by the Salford Health Authority Ethical Committee.

\section{TEST MEALS}

(1) Lipid emulsions were made using 20\% Intralipid (Pharmacia Ltd, Knowlhill, Milton Keynes, Beds, UK), a commercially prepared buffered iso-osmolar emulsion of soybean and egg lipid in water $(20 \%$ Intralipid comprises $8360 \mathrm{~kJ} / \mathrm{l}$ (2000 kcal/1), triglyceride $200 \mathrm{~g} / \mathrm{l}$, phospholipid $12 \mathrm{~g} / \mathrm{l}$, glycerol $22 \mathrm{~g} / \mathrm{l}$ ). Five 250 $\mathrm{ml}$ iso-osmolar test meals were then made by dilution of $20 \%$ Intralipid in iso-osmolar saline to provide lipid concentrations of $1.25,2.5,5$, 10 , and $20 \%(\mathrm{v} / \mathrm{v})$

(2) Glucose solutions were used to assess a

possible energy contribution to gastric relaxation. Two solutions $(250 \mathrm{ml})$ were used. One was $280 \mathrm{mmol} / \mathrm{kg}$ ( $5 \%$ intravenous infusion, $836 \mathrm{~kJ} / \mathrm{l}$; Baxter Healthcare, Thatford, Norfolk, $\mathrm{UK}$ ); the other was a $1200 \mathrm{mmol} / \mathrm{kg}$ solution (3344 kJ/l) made by the addition of glucose (Sigma-Aldrich, Gillingham, Dorset, UK) to $250 \mathrm{ml} 280 \mathrm{mmol} / \mathrm{kg}$ glucose. This second meal thus provided an energy load between that of the $5 \%(2090 \mathrm{~kJ} / \mathrm{l})$ and the $10 \%(4180$ $\mathrm{kJ} / \mathrm{l})$ lipid solutions.

(3) $\mathrm{NaCl}$ solutions provided non-nutrient meals of varying osmolality to explore the possible osmolar effects of lipid test meals. Four test solutions were made by adding $\mathrm{NaCl}$ (Sigma-Aldrich) to stock $300 \mathrm{mmol} / \mathrm{kg}$ 
intravenous saline solution $(0.9 \%$ sodium chloride i.v. solution; Baxter Healthcare) to provide solutions of $300,600,1200$, and 2400 $\mathrm{mmol} / \mathrm{kg}$ at a constant volume of $250 \mathrm{ml}$.

The osmolality of all meals was verified before delivery using a vapour pressure osmometer (Wescon Inc., Salt Lake City, Utah, USA), and all meals were delivered at room temperature.

A fine bore feeding tube ( $10 \mathrm{~F}$ diameter) was passed into the stomach to enable the test meals to be delivered directly, thus avoiding any effects of differences in meal palatability on gastric function.

Proximal gastric tone was assessed in each subject on each study day, using a previously developed and validated technique, ${ }^{8}$ both fasted and then after the administration of one of the test meals. In summary, the method involves serial measurements of intragastric pressure during stepwise inflation of a thin polythene bag (maximum volume $1200 \mathrm{ml}$ ) sited in the proximal stomach, via an attached 14 French gauge PVC catheter (RT20N Pennine Healthcare Products, Derby, UK). The proximal end of the catheter was connected to a strain gauge transducer calibrated against a commercial digital manometer (DPI 700; Druck Ltd, Grosby, $\mathrm{UK}$ ), capable of measuring intrabag pressure in the range $0-64 \mathrm{~mm} \mathrm{Hg}$ with a maximum error of $0.25 \mathrm{~mm} \mathrm{Hg}$. At each inflation volume, 12 consecutive readings of intrabag pressure were made at five second intervals and the mean of these values calculated.

PROTOCOL

Each meal was assessed in six subjects unless otherwise specified, and each subject received at least four test meals on separate days; all were studied in the morning after an overnight fast, lying supine in a quiet room. First, the bag was
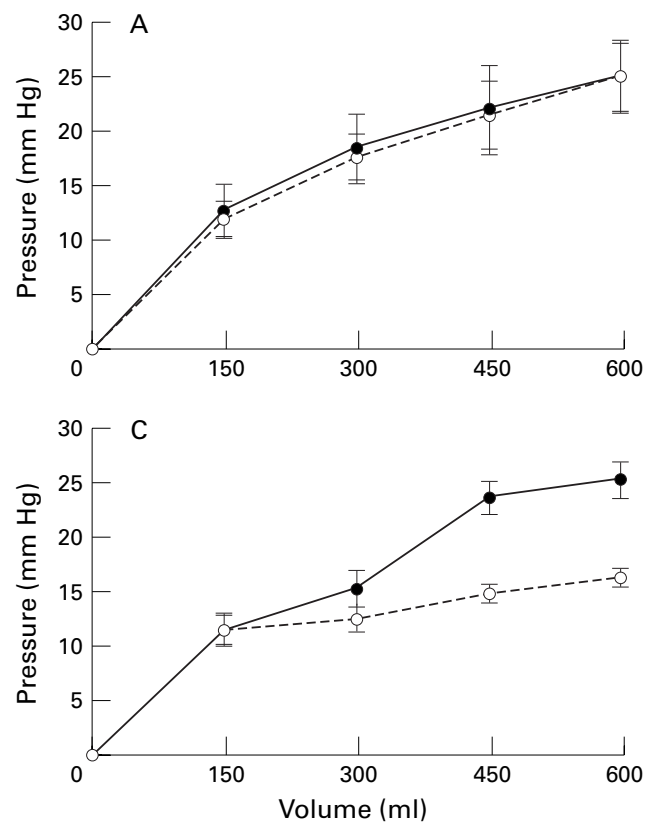

folded on the catheter, swallowed, and then advanced into the stomach. It was then partially inflated with $400 \mathrm{ml}$ air and withdrawn until resistance was met, indicating that its proximal end was sited at the lower oesophageal sphincter. After this, the bag was advanced $2 \mathrm{~cm}$, then fully deflated, and the catheter affixed to the subject's cheek with adhesive tape to prevent further catheter movement. After 10 minutes, the bag was progressively inflated in $30 \mathrm{ml}$ increments, at intervals of one minute, until the maximum tolerated volume was reached. Since previous studies in our laboratory had shown that the first distension series induced a variable relaxatory response but that subsequent fasting distensions produced a consistent pressurevolume relation, a second inflation series was performed immediately after the first and the data from this second fasted distension were used for comparison with the data obtained after the test meal. At the end of the second inflation, the bag was deflated for a further 10 minutes, then $250 \mathrm{ml}$ of one of the test meals was instilled into the stomach. Five minutes after the completion of meal delivery, the bag was reinflated as before.

SENSORY RESPONSES TO DISTENSION

At each inflation increment, subjects were asked to describe any sensations experienced, in particular, development of discomfort or nausea. Distension was discontinued when the subject reported discomfort. Subjects were kept unaware of the distending volume throughout the study.

GASTRIC TONE

An index of gastric tone was obtained by adding the values of intragastric pressure recorded for all the inflation volume steps from $30 \mathrm{ml}$ to
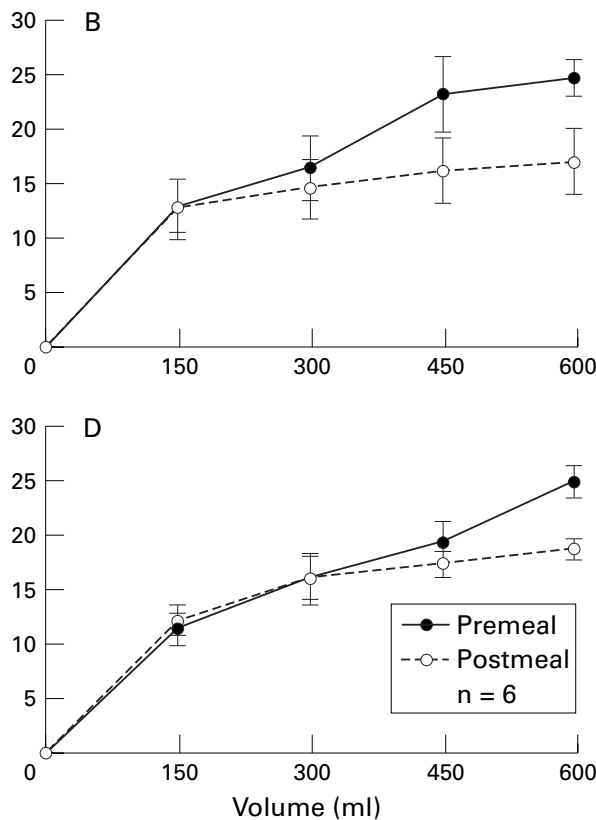

Figure 1 Effects of representative test meals on intragastric balloon pressure with increasing distension volumes are shown. Values are mean (SEM). A downward shift of the post-meal curve is indicative of a fall in proximal gastric tone. Hence the $1.25 \%$ lipid meal $(A)$ had no effect, while $10 \%$ lipid (B) was associated with a fall in proximal gastric tone $(p<0.05)$. A 2400 mmollkg saline solution $(C)$ was also associated with gastric relaxation $(p<0.05)$, while $10 \%$ glucose (1200 mmollkg) (D), which is equivalent to $8 \%$ lipid in its energy content, had no significant effect. 

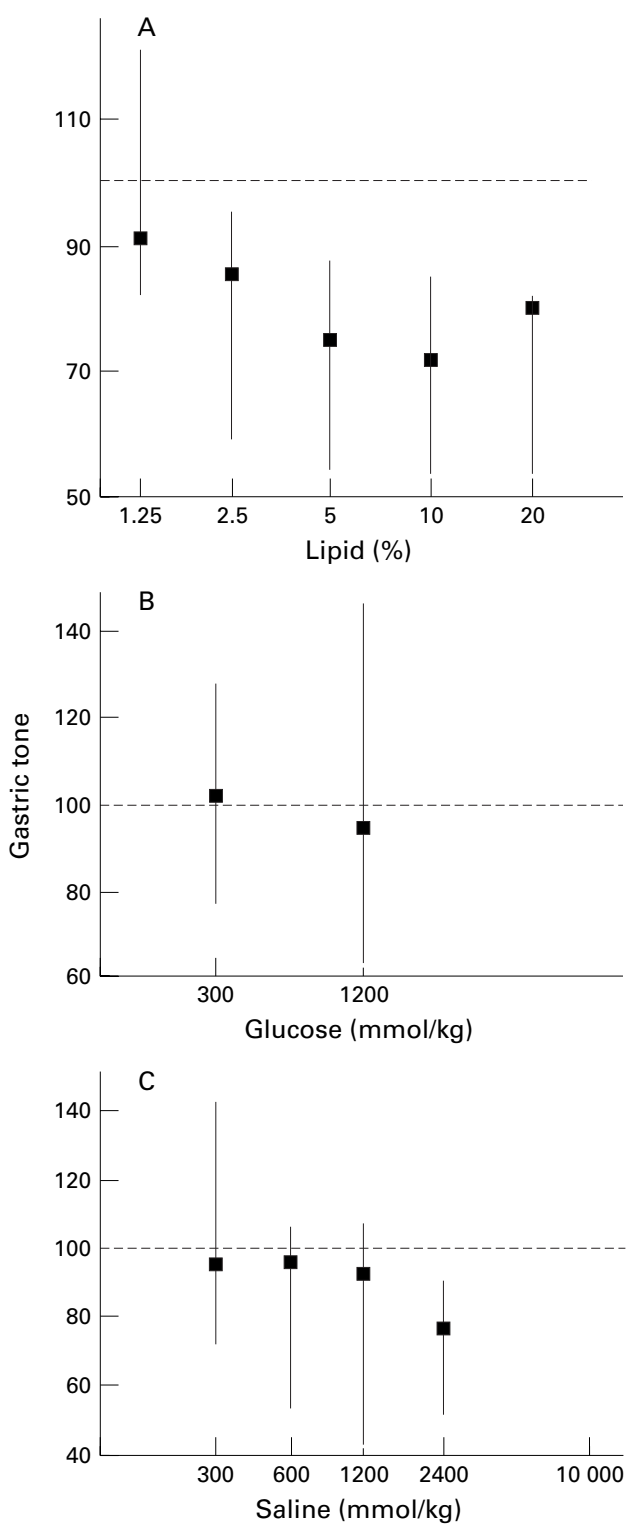

Figure 2 Plots showing the effect of the test meals on gastric tone. Results are median + range. Data shown are for $n=6$ subjects in all cases except for $2.5 \%$ lipid where $n=7$. The effect of each test meal is expressed as the percentage of the fasting value (fasting $=100 \%$ ). (A) The meals containing $2.5-20 \%$ lipid all caused significant fundal relaxation $(p<0.05$ for the difference in values obtained before and after the test meal) but the magnitude of this effect did not increase with increasing lipid concentration above $2.5 \%$. No effect was found for $1.25 \%$ lipid. (B) Neither glucose meal caused fundal relaxation $(p>0.05$ for the difference between values obtained before and after the test meal). The caloric value of $1200 \mathrm{mmol} / \mathrm{kg}$ glucose is equivalent to $8 \%$ lipid. (C) Significant gastric relaxation was observed only after the $2400 \mathrm{mmol} / \mathrm{kg}$ meal $(p<0.05$ for the difference between values obtained before and after the test meal).

the maximal tolerated volume during the second fasted inflation series and then dividing this value by the number of inflation steps. The procedure was repeated after the test meal administration. To avoid bias due to variable intragastric volumes before and after test meals, a single maximum intrabag volume was used as the endpoint for the calculation of tone-that is, the lower maximum volume from the pre- and post-meal distension series if the maximum tolerated volumes differed. Gastric tone is expressed in the text in $\mathrm{mm} \mathrm{Hg}$.
STATISTICAL ANALYSIS

The effect of the test meals on gastric tone was expressed in absolute terms as $\mathrm{mm} \mathrm{Hg}$ or as a percentage of the fasted value. Values in the text are median and range. All analyses were made using SPSS software. The significance of the differences between fasted and post-meal data were compared using the Wilcoxon matched pairs signed ranks test. Comparisons between test meal effects were made by analysis of variance and by the Mann-Whitney $U$ test. Differences were taken as biologically significant for values of $\mathrm{p}$ of less than 0.05 .

\section{Results}

GASTRIC PRESSURE-VOLUME RELATIONS

Figure 1 shows examples of pressure-volume curves, both fasting and after representative test meals. No differences in fasting tone were detectable between experimental groups. Values before and after the test meals were identical with $1.25 \%$ lipid, while $10 \%$ lipid produced a definite relaxation which was identical with that for $2.5-20 \%$ lipid. A $10 \%$ glucose solution, which is equivalent to $8 \%$ lipid in its energy content, had no significant effect. For saline to produce a consistent relaxation response, $2400 \mathrm{mmol} / \mathrm{kg}$ was required.

GASTRIC TONE RESPONSES

Figure 2 shows the gastric tone responses to lipid, glucose, and saline.

Effect of lipid

Intralipid $(1.25 \%)$ did not affect gastric tone (16.6 (11.5-24.9) $\mathrm{mm} \mathrm{Hg} v$ fasting 15.4 (12.8-27.9) $\mathrm{mm} \mathrm{Hg}$ ). Increasing lipid concentration to $2.5 \%$ and above was, however, associated with consistent reduction in tone in all individuals $(p<0.05)$. The relation between the magnitude of gastric relaxation achieved and lipid concentration delivered was non-linear, $2.5 \%$ lipid producing similar changes in tone to $20 \%$ lipid $(\mathrm{p}>0.05)$.

\section{Effect of energy composition}

Glucose did not cause a reduction in gastric tone either at $300 \mathrm{mmol} / \mathrm{kg}$ (18.2 (14.2-24.9) $\mathrm{mm} \mathrm{Hg} v$ fasting $18.5(15.7-23.6) \mathrm{mm} \mathrm{Hg}$ ) or at $1200 \mathrm{mmol} / \mathrm{kg}(16.0(11.4-22.4) \mathrm{mmHg} v$ fasting $15.6(11.6-17.9) \mathrm{mm} \mathrm{Hg})$.

Effect of osmolality

No effect on gastric tone was found after either iso-osmolar or 600 or $1200 \mathrm{mmol} / \mathrm{kg}$ saline. A reduction in gastric tone was, however, demonstrated after $2400 \mathrm{mmol} / \mathrm{kg}$ saline (14.3 (10.217.3) $\mathrm{mm} \mathrm{Hg} v$ fasting $18.0(15.0-19.5) \mathrm{mm}$ $\mathrm{Hg}$; $\mathrm{p}$ 0.05).

\section{SENSORY RESPONSES}

Maximal tolerated volumes after the $10 \%$ lipid (600 (300-750) $\mathrm{ml})$ or $20 \%$ lipid meal (600 $(270-750) \mathrm{ml}$ ) were not different from their respective fasting values $(645(420-750)$ and $680(450-750) \mathrm{ml})$. However, since lipid meals of $2.5 \%$ and above reduced gastric tone, maximal tolerated volumes after lipid were all associated with lower intragastric pressures than their respective fasted values. Nausea was 
reported by two volunteers after $20 \%$ lipid, but none developed in either subject after lower lipid concentrations despite similar gastric relaxation.

\section{Discussion}

The lipid and protein composition of a meal, together with its osmolality and $\mathrm{pH}$, are known to modulate gastric emptying, by actions on specific intestinal receptors. ${ }^{29}$ This gastric emptying delay is mediated by a number of functions, the major one in the case of lipid being proximal gastric relaxation. ${ }^{2}{ }^{3}$ Since meals matched for energy content and osmolality did not affect gastric tone, it can be concluded that a specific lipid sensitive receptor must be present in the human upper gut to modulate the gastric relaxation. Furthermore, this receptor appears to exhibit both threshold sensitivity (meals of less than $2.5 \%$ did not affect gastric tone) and saturability (no further response occurred above $2.5 \%$ lipid).

Since two of our subjects experienced nausea, and since it is known that nausea itself can reduce gastric tone, it could be argued that some of the effect of our lipid meals was nausea mediated. It seems unlikely that nausea confounded our results in any major way since maximum lipid related relaxation was reached in all subjects with $5 \%$ lipid, a concentration that was a quarter of that which was associated with nausea in the two individuals.

The energy content of meals has also been proposed to be a factor that determines gastric emptying. ${ }^{10}{ }^{11}$ In our study, however, replacement of lipid by a similar energy load of glucose did not cause gastric relaxation. This finding not only implies that lipid induced gastric relaxation is not mediated by its energy composition, but also that when glucose solutions do induce gastric relaxation they probably act by activation of osmoreceptors.

In contrast with energy content, the effects of meal osmolality on gastric function are well documented. ${ }^{912}$ Our studies show that osmolality and lipid composition act independently, however, since gastric relaxation was not replicated by non-lipid meals of matched osmolality. In fact, a consistent fall in gastric tone was only observed at an osmolality of 2400 $\mathrm{mmol} / \mathrm{kg}$, indicating that osmoreceptors probably only influence gastric efflux when meals of high osmolality are ingested.

The sensory perception data show that when relaxation was induced, the onset of discomfort occurred at the same distension volume but lower distending pressures, which suggests that stretch rather than tension of the gastric wall is the nociceptive trigger under the conditions of our study. A direct effect of lipid on pain threshold reduction has been previously postulated, ${ }^{13}$ but our data show no evidence for this unless the reduced intragastric pressure at the sensory endpoint is interpreted as "sensitisation".

While our studies in intact healthy volunteers cannot provide a detailed explanation for the mechanism by which lipid induced gastric relaxation occurs, it is known that in animals, lipids induce gastric relaxation only if the vagus nerves are intact. ${ }^{14}$ Furthermore, cholecystokinin (CCK), released from specialised duodenal mucosal cells by intraluminal fat, ${ }^{15}$ reduces proximal gastric tone $e^{1316}$ and inhibits gastric emptying $^{17}$ by activation of CCK receptors on vagal afferent nerves, ${ }^{18}$ which in turn activate inhibitory vagal efferents in the brainstem. It has also been suggested that vagal afferent fibres can be directly excited by lipid, ${ }^{19}{ }^{20}$ possibly by a vagal lipid receptor so that CCK release may not be obligatory. Whether one or both of these proposed effects exists in humans remains unknown. However, a reduction in human gastric tone by intraduodenal lipid was recently reported to be abolished by CCK-A receptor blockade ${ }^{17}$ suggesting a role for CCK in man.

In conclusion, our studies show that lipid meals reduce gastric tone by a lipid specific mechanism, which exhibits both a threshold and saturability and is independent of osmolality or energy content. Further studies are now required to determine the mechanism whereby this effect occurs, using the newly available CCK receptor antagonists.

The authors wish to acknowledge Mr N Higgs, who made the test meals and measured their osmolality, and Dr I Fairbain, who contributed to these studies as part of a medical student elective attachment. L E A T was a recipient of a fellowship grant from a covenant between the Interamerican Development Brant from a covenant between the Interamerica

1 Ewald CA, Boas J. Beitrage zur Physiologie und Pathologie der Verdauung. Archiv der Pathologie und Anatomie 1886;271.

2 Hunt JN, Knox MT. A relation between the chain length of fatty acids and the slowing of gastric emptying. F Physiol (Lond) 1968;194:327-36.

3 Houghton LA, Mangnall YF, Read NW. Effect of incorporating fat into a liquid test meal on the relation between intragastric distribution and gastric emptying in human volunteers. Gut 1990;31:1226-9.

4 Heddle R, Dent J, Read NW. Antropyloroduodenal motor responses to intraduodenal lipid infusion in healthy volunresponses to intraduodenal lipid infusid

5 Fraser R, Fone D, Horowitz M, et al. Cholecystokinin octapeptide stimulates phasic and tonic pyloric motility in humans. Gut 1993;34:33-7.

6 Tougas G, Anvari M, Dent J, et al. Relation of pyloric motilty to pyloric opening and closure in healthy subjects. Gut 1992;33:466-71.

7 Azpiroz F, Malagelada JR. Intestinal control of gastric tone. Am f Physiol 1985;249:G501-9.

8 Ahluwalia NK, Thompson DG, Barlow J, et al. Relaxation responses of the human proximal stomach to distension during fasting and after food. Am F Physiol 1993;40:G166-73.

9 Valanzuela JE, Defillipi C. Inhibition of gastric emptying in humans by secretin, the octapeptide of cholecystokinin and intraduodenal fat. Gastroenterology 1981;81:898-902.

10 Hunt JN, Stubbs DF. The volume and energy content of meals as determinants of gastric emptying. F Physiol (Lond) 1975;245:209-25.

11 McHugh PR, Moran TH. Calories and gastric emptying: a regulatory capacity with implications for feeding. $A m \mathfrak{F}$ Physiol 1979;236:R244-50.

12 Barker GR, Cochran CM, Corbett GA, et al. Glucose, glycine and diglycine in testmeals as stimuli to a duodenal osmoreceptor slowing gastric emptying. F Physiol (Lond) 1978;283:341-6.

13 Feinle C, D'Amato M, Read NW. Cholecystokinin-A receptors modulate gastric sensory and motor responses to gastric distension and duodenal lipid. Gastroenterology 1996; 110:1379-85.

14 Jahnberg TH, Abrahamsson G, Jansson G, et al. Gastric relaxatory response to feeding before and after vagotomy. relaxatory response to feeding before
Scand $\mathcal{F}$ Gastroenterol $1977 ; 12: 225-7$.

15 Liddle RA, Goldfine ID, Rosen MS, et al. Cholecystokinin bioactivity in human plasma: molecular forms, responses to feeding and relationship to gallbladder contraction. f Clin Invest 1985;75:1144-52

16 Raybould HE, Roberts ME, Dockray GJ. Reflex decreases in intragastric pressure in response to cholecystokinin in rats. Am F Physiol 1987;253:G165-70

17 Liddle RA, Morita ET, Conrad CK, et al. Regulation of gastric emptying in humans by cholecystokinin. $\mathcal{F}$ Clin Invest 1986;77:992-6.

18 Zarbin MA. Cholecystokinin receptors: presence and axonal flow in the rat vagus nerve. Life Sci 1981;29:697-705.

19 Raybould HE, Gayton RJ, Dockray GJ. Mechanisms of action of peripherally administered cholecystokinin octapeptide on brain stem neurons in the rat. $f$ Neurosci tapeptide on brain

20 Melone J. Vagal receptors sensitive to lipids in the small intestine of the cat. $\mathcal{F}$ Auton Nerv Syst 1986;17:231-41. 